\title{
Hypoxia and serum deprivation induces glycan alterations in triple negative breast cancer cells
}

\section{Amanda P.B. Albuquerque 1,2, Meritxell Balmaña ${ }^{3,4}$, Stefan Mereiter ${ }^{3,4}$, Filipe Pinto ${ }^{3,4}$, Celso A. Reis ${ }^{3,4,5,6 *}$ and Eduardo I.C. Beltrao ${ }^{1,2 *}$}

\author{
1 - Biomarkers in Cancer Research Group (BmC) - Federal University of Pernambuco (UFPE), 50670-901 Recife, \\ Pernambuco, Brazil. \\ 2 - Departament of Biochemistry- Federal University of Pernambuco (UFPE), 50670-901 Recife, Pernambuco, Brazil. \\ 3 - Instituto de Investigação e Inovação em Saúde, Universidade do Porto, 4200-135 Porto, Portugal \\ 4 - Institute of Molecular Pathology and Immunology, University of Porto, 4200-135 Porto, Portugal \\ 5 - Institute of Biomedical Sciences Abel Salazar, University of Porto, 4050-313 Porto, Portugal \\ 6 - Faculty of Medicine, University of Porto, 4200-319 Porto, Portugal \\ *Corresponding Authors: celsor@ipatimup.pt and ebeltrao@hotmail.com
}

Originally published in Biol. Chem. 2018; 399(7): 661-672. DOI: 10.1515/hsz-2018-0121

\begin{abstract}
Triple negative breast cancer (TNBC) is a major global public health problem. The lack of targeted therapy and the elevated mortality evidence the need for better knowledge of the tumor biology. Hypoxia and aberrant glycosylation are associated with advanced stages of malignancy, tumor progression and treatment resistance. Importantly, serum deprivation regulates the invasive phenotype and favors TNBC cell survival. However, in TNBC, the role of hypoxia and serum deprivation in the regulation of glycosylation remains largely unknown. The effects of hypoxia and serum deprivation on the expression of glycosyltransferases and glycan profile were evaluated in the MDAMB-231 cell line. We showed that the overexpression of HIF-1 $\alpha$ was accompanied by acquisition of epithelial-mesenchimal transition features. Significant upregulation of fucosyl- and sialyltransferases involved in the synthesis of tumorassociated carbohydrate antigens was observed together with changes in fucosylation and sialylation detected by Aleuria aurantia lectin and Sambucus nigra agglutinin lectin blots. Bioinformatic analysis further indicated a mechanism by which HIF-1 $\alpha$ can regulate $S_{3} G A L 6$ expression and the relationship within the intrinsic characteristics of TNBC tumors. In conclusion, our results showed the involvement of hypoxia and serum deprivation in glycosylation profile regulation of TNBC cells triggering breast cancer aggressive features and suggesting glycosylation as a potential diagnostic and therapeutic target.
\end{abstract}

Keywords: cancer cell biology; glycosylation; glycosyltransferases; hypoxia; serum deprivation; triple negative breast cancer. 


\section{INTRODUCTION}

Breast cancer is the second most common cancer worldwide, accounting for $25 \%$ of all female cancer incidences (Ferlay et al., 2015), and is responsible for the highest number of pathologyrelated deaths in women. Differences in the phenotype and expression of certain proteins in breast cancer subtypes reflect the heterogeneity of these tumors resulting in important consequences for disease progression, treatment response and patient outcome (Perou et al., 2000; Chikarmane et al., 2015). The triple negative breast cancer (TNBC) subtype is the most aggressive form of breast cancer, occurring frequently in young women and presenting the poorest overall survival. TNBC accounts for $12 \%$ of all breast cancers diagnosed and due to the lack of expression of the key receptors, estrogen, progesterone and human epidermal growth factor receptor 2, targeted therapies are currently unavailable (Foulkes et al., 2010; Howlader et al., 2014).

Present in $25-40 \%$ of metastatic breast cancers, intratumoral hypoxia is associated with epithelial-mesenchymal transition (EMT), invasion, metastasis, resistance to chemotherapy and radiotherapy, recurrence and consequently, poor prognosis (Lundgren et al., 2007; Semenza, 2012; Wang et al., 2014b). Furthermore, hypoxia together with nutrient deprivation, a common characteristic of locally advanced tumors, favor aggressive cancer phenotypes by influencing specific signalling pathways regulating cell proliferation and survival, adaptive immune responses, cell metabolism and eventually metastasis (Badr et al., 2015; Jung et al., 2015a,b; Marchiq and Pouysségur, 2016). In TNBC cells, hypoxia response is often triggered by HIF-1 $\alpha$ accumulation and nuclear translocation leading to the aforementioned phenotypes (Wang et al., $2014 a, b)$. Thus, the analysis of the effects of hypoxia and serum deprivation may be promising for the discovery of new therapeutic targets for TNBC.

Glycosylation changes are a universal feature of malignant transformation and tumor progression (Pinho and Reis, 2015). In the TNBC subtype, the expression profile of several glycosyltransferases was correlated with clinical and survival data (Ashkani and Naidoo, 2016), and alterations in $N$ and $O$-glycosylation patterns have been suggested as markers for prognostic and treatment stratification of breast cancer patients (Milde-Langosch et al., 2014; Potapenko et al., 2015). Recently, Greville and collaborators suggested that the induction of a metabolic shift could alter breast cancer glycosylation through increased availability of sugar nucleotides, as well as

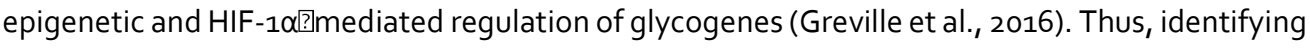
a possible link between hypoxia and the regulation of the glycosylation.

Moreover, alterations in glycosylation studied under serum deprivation, an approach commonly used to mimic the insufficient nutrients supply observed in several solid tumors, was identified as a cancer cell survival strategy (Britain et al., 2017). Despite several studies reporting different roles of serum deprivation, such as the regulation of mRNA transcription (Nutt and Lunec, 1996; Mahmoodi et al., 2015), induction of invasive phenotype (Reshkin et al., 2000; Ye et al., 2013), evasion of apoptosis (Jung et al., 2015b) or chemoresistance (Yakisich et al., 2017), the effects on the regulation of the glycosylation have hardly been explored. 
Considering the pivotal role of hypoxia in cancer glycosylation (Koike et al., 2004; Belo et al., 2015; Peixoto et al., 2016) as well as the effects of serum deprivation in TNBC progression (Ye et al., 2013; Jung et al., 2015b), we decided to investigate the alterations in the main fucosyl- and sialyltransferases involved in tumor associated carbohydrate antigens' biosynthesis after submitting the TNBC cell line MDA-MB-231 to hypoxia and serum deprivation. Moreover, we evaluated in silico the expression of these glycosyltransferases in TNBC tumors. Finally, we investigated a possible mechanism involved in the regulation of these fucosyl- and sialyltransferases.

\section{RESULTS}

Hypoxia and serum deprivation induce morphological changes and epithelialmesenchymal transition of breast cancer cells

In order to validate our hypoxic system, we evaluated the activation of the hypoxia marker HIF$1 \alpha$ in MDA-MB-231 breast cancer cell line when cells were subjected to hypoxia. Cells were exposed to either hypoxia $\left(1 \% \mathrm{O}_{2}\right)$ or normoxia $\left(21 \% \mathrm{O}_{2}\right)$ for $48 \mathrm{~h}$. Our analysis showed a striking increase of HIF-1 $\alpha$ after $48 \mathrm{~h}$ of exposure to hypoxia in relation to normoxia. This increase was more marked when cells were subjected to both hypoxia and serum deprivation (Supplementary Figure $1 \mathrm{~A}$ ). In addition to a general increase, the transcription factor HIF-1 $\alpha$ translocated from the cytoplasm into the nucleus as a response to hyopoxia (Supplementary Figure $1 \mathrm{~B}$ ).

In addition, a morphological characterization of cells subjected to hypoxia and serum deprivation was performed. Immunostaining of $\alpha$-tubulin showed that cells under hypoxia/serum deprivation conditions acquired larger intercellular spaces and a more elongated shape (Figure $1 \mathrm{~A}$ ), when compared with cells under normoxia or serum supplementation (Han et al., 2015).

The morphology alterations observed together with the literature describing the role of hypoxia in promoting EMT (Tan et al., 2018), we further characterize our cell model with key EMT markers. The expression of the epithelial marker E-cadherin, an important cell-cell adhesion protein, showed a striking decrease under hypoxic and serum deprivation conditions (Figure $1 \mathrm{~B}$ ). Concomitantly, the mesenchymal marker vimentin was abundantly expressed in MDA-MB-231 cells under hypoxic conditions (Figure $1 \mathrm{C}$ ). Cells subjected to serum deprivation and hypoxia (Ho) showed the most defined EMT, altogether confirming the transition to a more aggressive phenotype of the cells subjected to stress conditions. Despite the aforementioned morphological alterations, no major alterations in cell viability were observed under any of the studied conditions (Figure 1D).

\section{Fuscosyltransferase transcription analysis of breast cancer cells under hypoxia and serum deprivation}

In order to evaluate the glycosyltransferase status of the cells subjected to hypoxia and serum deprivation, we performed a broad transcription analysis of the main fucosyltransferases, including the ones involved in the formation of tumor associated carbohydrate antigens. Our results showed

\section{西}


that after $48 \mathrm{~h}$ of exposure to hypoxia and serum deprivation, significant changes of FUT1, FUT2, FUT $_{3}$, FUT $_{5}$, FUT6, FUT7 and FUT11 gene expression occurred in MDA-MB-231 cells (Figure 2). Most of the alterations were upregulations with hypoxia and serum deprivation presenting the strongest changes, suggesting a cumulative effect. An exception were FUT4 and FUT10, in which hypoxia led to an expressional upregulation but a downregulation in serum deprivation. The fucosyltransferase FUT8, responsible for core fucosylation, did not show significant changes.

\section{Sialyltransferase transcription analysis of breast cancer cells under hypoxia and serum deprivation}

Similar to fucosyltransferases, hypoxia with and without serum deprivation induced alterations in the expression of sialyltransferases. In MDA-MB-231 cells, hypoxia and serum deprivation induced a significant upregulation of $S_{3} G A L_{3}, S_{3} G A L_{4}, S T_{3} G A L 6, S T 6 G A L N A C_{1}$ silalyltransferases (Figure 3). Whereas ST6GALNAC5 shows consistent downregulation in hypoxia, ST6GALNAC2 exhibits a complex expression profile, being downregulated under serum deprivation with normoxia but upregulated under serum deprivation with hypoxia.

Our data demonstrates that the expression signature of fucosyl- and sialyltransferases was extensively affected by hypoxia and serum deprivation conditions.

\section{Bioinformatic analysis of transcriptomic data}

The previously described expressional changes of fucosyltransferases and sialyltransferases are particularly interesting when the intrinsic expression status of the respective genes of MDA-MB-231 is taken into account. For this purpose, the relative expression levels of fucosyl- and sialyltransferases of MDA-MB-231 were compared with 55 other breast cancer cell lines transcriptionaly analysed by Barretina et al. (2012). First, the TNBC cell lines were grouped and compared to the remaining breast cancer cell lines to identify the pattern expression of the selected glycosyltransferases. Then, the glycosyltransferase genes that were cell line intrinsically down- or overexpressed were identified (Figure $4 \mathrm{~A}$ ). This data complements the alterations observed under hypoxic or serum deprivation conditions. In this regard, FUT5 and ST3GAL6 were innately overexpressed glycosyltransferases of MDA-MB-231. The cumulative and highly significant further upregulation of FUT5 and ST3GAL6 in hypoxia and under serum deprivation foreshadows therefore a strong effect on the cellular glycosylation. Interestingly, the high expression levels of FUT5 and ST3GAL6 of the TNBC cell line MDA-MB-231 are a typical feature of TNBC tumors of patients (Figure $4 \mathrm{~B}$ ).

\section{Hypoxia and serum deprivation induces altered glycosylation of breast cancer cells}

The glycoprofile of MDA-MB-231 cells was studied to address whether the changes found at the transcriptomic level were translated into different glycosylation of proteins. For this purpose, cells were cultured under the different conditions for $72 \mathrm{~h}$. Analysis with Sambucus nigra agglutinin (SNA) confirmed a significant increase of $\alpha_{2}, 6$ protein sialylation in both hypoxic conditions ( $\mathrm{H}_{1} \mathrm{O}$ and $\mathrm{Ho}$ ) in agreement with the strong increase observed in ST6GALNAC1 and ST6GALNAC2 expression by quantitative real-time polymerase chain reaction (RT-qPCR) (Figure $5 \mathrm{~A}$ ). Evaluation with the Aleuria 
aurantia lectin (AAL) showed that hypoxia and serum deprivation did not promote alterations in the total amount of protein fucosylation after $72 \mathrm{~h}$ (data not shown). Considering that glycosylation is a post-translational modification and that changes in the glycan expression require the translation of the glycosyltransferases, we hypothesized that $72 \mathrm{~h}$ of the experimental condition could be a limiting time for the glycosylation machinery to display these differences. For this reason, we evaluated fucosylation after subjecting the cells to hypoxia and serum deprivation for 6 days. Indeed, differences were displayed by AAL especially striking in serum deprived conditions, which is in accordance with the transcription expression displayed by FUT5 and FUT6 (Figure $5 \mathrm{~B}$ ). Altogether these results show that the complex regulation of fucosyl- and sialyltransferase expression induced by hypoxia and serum deprivation modulate the cellular glycosylation and might thereby contribute to a more aggressive phenotype of TNBC cells.

\section{Hif-1 $\alpha$ transcription factor interacts with glycosyltransferase promoters}

To understand the mechanism by which hypoxia modulates the expression of glycosyltransferases, we evaluated the transcriptional activation of the sialyltransferase ST3GAL6. The chromatin immunoprecipitation sequencing (ChIP-seq) information from the GTRD database revealed the presence of at least four DNA-binding motifs for HIF-1 $\alpha$ and its partner HIF-1 $\beta$ (ARNT) in the promoter region of $S_{3} G A L 6$ gene. This region also correlated with the presence of the transcription promoting histone marker $\mathrm{H}_{3} \mathrm{~K}_{4} \mathrm{me}_{3}$ for the opening of the chromatin and the activation of gene transcription (polymerase II) (Figure 6).

\section{DISCUSSION}

Here, we present a systematic study on transcriptional changes of fucosyl- and sialyltransferases under hypoxic and serum deprived conditions in the TNBC cell line MDA-MB-231. We further demonstrate that the induction of the HIF-1 $\alpha$ cascade leads not only to the expression of EMT markers but also to marked changes in cellular glycosylation.

HIF-1 $\alpha$ is known to be involved in the aggressive phenotype of TNBCs, with high expression levels associating with worse prognosis and increased metastatic potential (Jeon et al., 2013; Wang et al., 2014a). Here, we present that the increase in total HIF-1 $\alpha$ and its translocation to the nucleus appears to be a corner stone for the transcriptional alteration of fucosyl- and sialyltransferases ultimately resulting in a change in cellular glycosylation. Among the observed changes in glycosyltransferase expression, the upregulation of ST3GAL6 was the most prominent. The observed significant upregulation of ST3GAL6 in MDA-MB-231 under hypoxic and serum deprived conditions stood out as the cell line showed already comperatively high basal expression levels of this gene. Here, we have described that the promoter region of ST3GAL6 has four HIF-1 $\alpha$ binding sites, suggesting ST3GAL6 as a major responsive gene in hypoxia and stress response in TNBC. This is further underlined by the significant higher expression of $\mathrm{ST}_{3} G A L 6$ in TNBC tumors compared to the other breast cancer subtypes.

Our results were in agreement with other studies, showing that HIF-1 $\alpha$ is essential for the dynamic transition of breast cancer tumorigenic states (Kuo et al., 2016) and involved in the breast cancer aggressiveness and tumor resistance by epigenetic regulation of glycosylation-related genes . 
(Greville et al., 2016). In addition, several studies have shown that the morphological changes occurring during EMT are accompanied by a metabolic shift towards glucose metabolism reprograming and aberrant glycosylation (Li and Li, 2015; Lucena et al., 2016; Carvalho et al., 2018).

Although it has long been known that poor availability of nutrients widely exists in breast cancer due to insufficient blood supply (Vaupel and Hockel, 2000), the effects of serum deprivation in the glycosylation of breast cancer cells are poorly understood. In this context, the present work sets the basis for the comprehension of the impact of hypoxia and serum deprivation in glycosylation of TNBC cell model. It is important to highlight that the conjunction of hypoxia and serum deprivation is a culture condition mimics the in vivo tumor microenvironment where nutrient deprivation and hypoxia co-exists (Jung et al., 2015a, b; Wu et al., 2015).

Our results showed for the first time, that hypoxia together with serum deprivation in breast cancer cells led to morphological alterations in the cytoskeleton organization. Moreover, these changes were accompanied with reduced expression of E-cadherin concomitant with an increased expression of vimentin. Similar alterations were observed in previous studies that showed EMT activation and increased invasion and spread under hypoxia and serum deprivation conditions (Wang et al., 2014b; Jung et al., 2015b; Kondavetti et al., 2015; Peixoto et al., 2016). Further investigation will be needed to fully understand the mechanism by which the metabolic reprogramming may be involved in the EMT transition induced by hypoxia and serum deprivation in TNBC.

A hypoxia-induced EMT breast cancer model showed that the abnormal glycosyltransferase expression was involved in the cell migration and expression of EMT markers regulation (Tan et al., 2018). These results are in agreement with our morphological changes and results obtained by RTqPCR results for key glycogenes. The importance of the Warburg effect for TNBC cells (Choi et al., 2013; Kim et al., 2013), leads us to speculate that the upregulation of fucosyl- and sialyltransferases in MDA-MB-231 cells by hypoxia and serum deprivation may be involved in the cell adaptation to metabolic stress conditions. In agreement with this hypothesis, Jones and collaborators reported an association between altered expression of ST6Galı sialyltransferase and increased mRNA levels of glucose transporters under hypoxia in ovarian and pancreatic cancer cells (Jones et al., 2018).

The relevance of the glycosyltransferase gene signature for cancer classification and survival was previously reported (Ashkani and Naidoo, 2016). We observed a significant induction of the FUT1/2 expression under hypoxia together with serum deprivation in MDA-MB-231 cells. Although little is known about the regulation of $\alpha_{1,2}$-fucosylation, there are evidences that metastatic capacity and hypoxia may be associated to the increased expression of FUT1/2 (Mejías-Luque et al., 2007; Zi et al., 2013; Belo et al., 2015).

We also reported altered expression profiles of $\alpha 1,3 / 4$-fucosyltransferases and $\alpha 2,3$-sialyltransferases

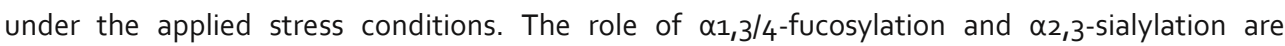
commonly linked in tumor progression and metastasis through the expression of sialyl Lewis antigens, which are related to evasion of immune cell recognition and to cell extravasation (Higai et al., 2006; Cazet et al., 2010; Julien et al., 2011; Monzavi-Karbassi et al., 2013; Shirure et al., 2015; Natoni and O'Dwyer, 2016; Carrascal et al., 2017). In addition we also demonstrated that hypoxia and serum deprivation induces upregulation of the $\alpha 2,6$-sialyltransferases ST6GALNAC 1 and 
ST6GALNAC2. This increased gene expression was reflected in increased $\alpha 2,6$-sialylation as demonstrated by SNA lectin. The aberrant increase of $\alpha 2,6$-sialylation is described to promote tumor cell survival and metastasis (Zhuo and Bellis, 2011; Schultz et al., 2012). Remarkably, Britain and collaborators demonstrated a protective effect of the increased $\alpha 2,6$-sialylation to serum withdrawal (Britain et al., 2017).

The sialyltransferase ST6GaINAC1 shows very low expression levels in healthy mammary glands as well as in most carcinoma cell line models of the breast (Julien et al., 2001). However, STn, the glycan product of ST6GalNAC1, is observed in around 30\% of all breast carcinomas and more frequently in estrogen-receptor negative tumors (Sewell et al., 2006; Julien et al., 2012). We confirm here the baseline expression of ST6GALNAC1 of MDA-MB-231 under normal conditions and showed a more than 100 -fold increase of ST6GALNAC1 under hypoxia and serum deprivation. This suggests that these adverse conditions may be a regulatory mechanism underlying STn expression in TNBC.

The majority of cancer biomarkers that are currently used in the clinical settings are glycoproteins, although their detection is mainly based in the protein backbone detection (Reis et al., 2010; Henry and Hayes, 2012). Indeed, there has been a great interest on finding novel biomarkers based on the glycan detection which lead to higher specificity and sensitivity. In most cancers, fucosylation and sialylation expression are found to be significantly modified, showing potential as predictive markers of poor outcome in breast cancer patients (Kyselova et al., 2008; Alley and Novotny, 2010; Aloia et al., 2015). With this study, we provide evidences of the role of hypoxia, nutrient deprivation and glycosylation in TNBC biology, and we open a new window for future studies to discover biomarkers of prognosis and of treatment response, especially relevant for the TNBC which lacks specific target for personalized treatment.

In conclusion, the current study evidenced the involvement of hypoxia and serum deprivation in the regulation of fucosyl- and sialyltransferases concomitant with morphological changes and the induction of EMT. These results support that further analysis on the effect of hypoxic microenvironment and/or nutrient deprivation and their translation into specific glycan-related antigens, such as tumor associated carbohydrate antigens, are required.

\section{MATERIALS AND METHODS}

\section{Cell culture}

MDA-MB-231 (Triple negative, basal-like subtype) breast cancer cell line was obtained from the American Type Culture Collection (ATCC, USA). Cells were cultured in Dulbecco's Modified Eagle's Medium (DMEM) (Gibco, Life Technologies, Waltham, MA, USA) supplemented with $10 \%$ fetal bovine serum (FBS, Gibco, Life Technologies) with medium renewal every $48 \mathrm{~h}$. Cells were maintained at $37^{\circ} \mathrm{C}$ in a $5 \% \mathrm{CO}_{2}$ humidified atmosphere. Cultured cells were routinely tested for mycoplasma contamination by PCR amplification for mycoplasma pulmonis UABCTIP, mycoplasma penetrans HF-2 and mycoplasma synoviae 53. MDA-MB-231 identity was confirmed by STR profiling. 


\section{Hypoxic and serum deprivation conditions}

After three generations, MDA-MB-231 cells were incubated for the corresponding time-points at $37^{\circ}$ C under the following conditions: normoxia (21\% O 2/94.7\% N2/5\% CO2) in DMEM 10\% FBS - control group ( $\mathrm{N}_{10}$ ); normoxia $\left(21 \% \mathrm{O}_{2} / 94.7 \% \mathrm{~N} 2 / 5 \% \mathrm{CO}_{2}\right.$ ) in DMEM/without FBS - No group; hypoxia ( $1 \%$ $\left.\mathrm{O}_{2} / 94.7 \% \mathrm{N2} / 5 \% \mathrm{CO}_{2}\right)$ in DMEM/10\% FBS - $\mathrm{H}_{1}$ o group; and hypoxia ( $\left.1 \% \mathrm{O}_{2} / 94.7 \% \mathrm{~N} 2 / 5 \% \mathrm{CO}_{2}\right)$ in DMEM/without FBS - Ho group. For hypoxia, a BINDER C-150 incubator (BINDER GmbH, Tuttlingen, Germany) was used.

\section{Cell viability assay}

The effect on cell viability produced by hypoxia and FBS deprivation was determined by cell proliferation assay (CellTiter $96^{\circledR}$ Aqueous One Solution Cell Proliferation Assay, Promega, Madison, WI, USA). Briefly, 3000 cells per well were seeded in 96 -well plates for $24 \mathrm{~h}$. Then, cells were PBS washed and subjected to normoxia or hypoxia containing DMEM or DMEM supplemented with $10 \%$ FBS. Cell viability was assessed after $48 \mathrm{~h}$ by adding $20 \mu \mathrm{l}$ of MTS to the medium, incubated for $2 \mathrm{~h}$ and read at $490 \mathrm{~nm}$ in an automated microplate reader (BioTek, Winooski, VT, USA). Three replicates for each condition were used. Two independent experiments were conducted.

\section{RNA isolation, CDNA synthesis and RT-PCR analysis}

Forty-eight hours after incubation under $\mathrm{N}_{1} \mathrm{O}, \mathrm{No}, \mathrm{H}_{10}$ and Ho conditions, total RNA was extracted using TRIzol Reagent (Sigma-Aldrich, St. Louis, MI, USA). Three micrograms of RNA were reverse transcribed with random primers using the SuperScript ${ }^{\circledR}$ IV Reverse Transcriptase Kit (Invitrogen, Carlsbad, CA, USA). RT-qPCR was performed with diluted cDNA (20-fold), $10 \mu \mathrm{m}$ of each primer, $5 \mu \mathrm{l}$ $\mathrm{SYBR}^{\circledR}$ Green Master Mix ( $1 \mathrm{X}$ ) (Thermo Fisher Scientific; former Savant, Waltham, MA, USA) and ultrapure water to a final volume of $10 \mu \mathrm{l}$ using the $A B I 7500$ (Applied Biosystems, Foster City, CA, USA). The primers used are listed in Supplementary Table 1. Normalization of target gene abundance was performed with ACTB/PPIA. Two independent experiments and three technical replicates per condition were performed.

\section{Immunofluorescence}

Cells were grown on coverlips under the different experimental conditions. Then, cells were fixed with $4 \%$ paraformaldehyde (Alfa Aesar, Haverhill, MA, USA) or methanol (Fisher Scientific, Waltham, MA, USA) at RT for 20 min and permeabilized with $0.5 \%$ triton $\mathrm{X}-100$ in PBS at $4^{\circ} \mathrm{C}$ for $10 \mathrm{~min}$, and blocked in 20\% normal goat non-immune serum (Dako, Agilent, Santa Clara, CA, USA) in PBS, 10\% BSA. Then, primary antibodies incubation was performed overnight at $4^{\circ} \mathrm{C}$, washed with PBS and incubated with the corresponding fluorescently-labeled secondary antibody for $1 \mathrm{~h}$ at RT. After washing, cell nuclei were stained with $1 \mathrm{~g} / \mathrm{ml}$ of 4,6-diamidino-2-phenylindole (DAPI) for $15 \mathrm{~min}$ at RT. Coverslips were mounted in VectaShield (Vector Laboratories, Burlingame, CA, USA) and visualized under a fluorescent microscope (Zeiss Axio Imager Z1 Apotome). The antibodies and concentrations used are listed in Table 1. 


\section{In silico transcription analysis}

The log2 median centered gene expression data of human cancer cell lines and breast cancer patients were extracted from the OncomineTM platform (www.oncomine.org) (Rhodes et al., 2004). The gene expression profile analysis of the cell lines was performed as described before (Duarte et al., 2017). Briefly, gene expression values of 913 human cancer cell lines of the Barretina CellLine data set (Barretina et al., 2012) were extracted and each gene's expression value was normalized into values between $\mathrm{o}$ and 100 . The median for each normalized gene probe was determined among the 54 human breast cancer cell lines and among the 25 TNBC cell lines. We defined the normal expression range for each gene transcript as the median \pm 10 . The Curtis Breast dataset comprising 1989 human breast carcinomas was used for the gene expression analysis of primary tumors of breast cancer patients (Curtis et al., 2012).

\section{Immunoblotting}

Total cellular proteins were extracted and quantified using the DC protein assay (BioRad, Hercules, CA, USA). Equal amounts of cellular protein lysates were electrophoresed on SDS-PAGE gel and transferred to nitrocellulose membranes (GE Healthcare Life Sciences, Chicago, IL, USA). The membranes were blocked in $5 \%$ non-fat milk in TBS 0.1\%Tween 20 (TBST) before incubation with primary antibodies, or in $2 \%$ polyvinylpyrrolidone (PVP) (Sigma-Aldrich, St. Louis, MI, USA) in TBS prior to incubation with biotinylated lectins. After washing, the membranes were incubated with secondary antibodies or streptavidin conjugated with horseradish peroxidase. ECL-plus (GE Healthcare) was used as a developer. The antibodies and lectins specifications and the concentrations used are listed in Table 1. SNA specificity was tested by comparing the lectin reactivity of a neuraminidase-digested (neuraminidase from Clostridium perfringens, Sigma-Aldrich) sample with their non-treated control (Supplementary Figure 2).

\section{Analysis of enriched transcription factor binding sites}

The promoter region of $S T_{3} G A L 6$ gene was identified using the Ensembl regulatory elements (content of $\mathrm{CpG}$ methylation sites, polymerase II activation, presence of activated histone $\mathrm{H}_{3} \mathrm{~K}_{4} \mathrm{me} 3$ and the inhibitory histone marker $\mathrm{H}_{3} \mathrm{k}_{2} 7 \mathrm{me2}$ ) (www.ensembl.org). Prediction of HIF1 $\alpha$ ::ARNT binding sites was performed using the software GTRD v18.01 (Yevshin et al., 2017). GTRD provided the most complete collection of uniformly processed ChIP-Seq data to identify transcription factor binding sites for human. The GTRD aggregated ChIP-Seq data from GEO was reprocessed with an unified pipeline using four different peak calling tools (macs, gem, pics, sissrs). The ChIP-seq signals identified for HIF1a::ARNT on the ST3GAL6 promoter region were aligned with CpG methylation sites, polymerase II, $\mathrm{H}_{3} \mathrm{~K}_{4}$ me3 and $\mathrm{H}_{3} \mathrm{~K}_{2} 7 \mathrm{me} 2$ to assist the definition of the activation or repression of the $S_{3} G A L 6$ expression. The motif discovery for the ChIP-Seq peaks identified in the ST3GAL6 promoter was assessed using known DNA-binding motifs for $\mathrm{HIF}_{1} \alpha$ and $\mathrm{HIF}_{1} \beta$ (ARNT) described in the JASPAR database (Khan et al., 2018). The motifs are specified using position weight matrices that assign weights to each nucleotide in each position of the DNA binding motif for a transcription factor or a group of them. 


\section{Statistical analysis}

Student's $t$-test and one-way analysis of variance (ANOVA) were performed to evaluate the statistical difference using GraphPad Prism (version 6) software. $p \leq 0.05$ values were considered significant $(*), p \leq 0.01(* *), p \leq 0.001(* * *)$ and $p \leq 0.0001(* * * *)$.

Acknowledgments: We thank the following funding agencies: Coordenação de Aperfeiçoamento de Pessoal de Nível Superior (CAPES), Fundação de Amparo à Ciência e Tecnologia de Pernambuco (FACEPE). This work was also funded by the project NORTE-01-0145-FEDER-000029, supported by Norte Portugal Regional Programme (NORTE 2020), under the PORTUGAL 2020 Partnership Agreement, through the European Regional Development Fund (ERDF); and by FEDER - Fundo Europeu de Desenvolvimento Regional funds through COMPETE 2020 - Operational Programme for Competitiveness and Internationalisation (POCI), Portugal 2020, and by Portuguese funds through FCT (Fundação para a Ciência e a Tecnologia)/Ministério da Ciência, Tecnologia e Inovação in the framework of the project 'Institute for Research and Inovation in Health Sciences' (POCl-01-0145FEDER-007274), the project POCI-01-0145-FEDER-016585 (PTDC/BBB EBI/0567/2014), and by EU 7th framework programme ITN 316929, and by the European Union's Horizon 2020 research and innovation programme under the Marie Sklodowska-Curie grant agreement No. 74888o. F. Pinto received a fellowship from FCT (SFRH/BPD/115730/2016).

\section{REFERENCES}

Alley, W.R. Jr. and Novotony, M.V. (2010). Glycomic analysis of sialic acid linkages in glycans derived from blood serum glucoproteins. J. Proteome. Res. 9, 3062-3072.

Aloia, A., Petrova, E., Tomiuk, S., Bissels, U., Deas, O., Saini, M., Zickgraf, F.M., Wagner, S., Spaich, S., Sutterlin, M., et al. (2015). The sialyl-glycolipid stage embryonic antigen 4 marks a subpopulation of chemotherapy resistant breast cancer with mesenchymal features. Breast Cancer Res. 17, 146.

Ashkani, J. and Naidoo, K.J. (2016). Glycosyltransferase gene expression profiles classify cancer types and propose prognostic subtypes. Sci. Rep. 6, 26451.

Badr, H.A., AlSadek, D.M., Mathew, M.P., Li, C.Z., Djansugurova, L.B., Yarema, K.J., and Ahmed, H. (2015). Nutrient-deprived cancer cells preferentially use sialic acid to maintain cell surface glycosylation. Biomaterials 70, 23-36.

Barretina, J., Caponigro, G., Stransky, N., Venkatesan, K., Margolin, A.A., Kim, S., Wilson, C.J., Lehar, J., Kryukov, G.V., Sonkin, D., et al. (2012). The cancer cell line encyclopedia enables predictive modelling of anticancer drug sensitivity. Nature 483, 603-607.

Belo, I., Vliet, S., Maus, A., Laan, L.C., Nauta, T.D., Koolwijk, P., Tefsen, B., and van Die, I. (2015). Hypoxia inducible factor 1 a down regulates cell surface expression of a1,2-fucosylated glycans in human pancreatic adenocarcinoma cells. FEBS Lett. 589, 2359-2366.

Britain, C.M., Dorsett, K.A., and Bellis, S.L. (2017). The glycosyltransferase ST6Gal-I protects tumor cells against serum growth factor withdrawal by enhancing survival signaling and proliferative potential. J. Biol. Chem. 11, 4663-4673.

Carrascal, M.A., Silva, M., Ramalho, J.S., Pen, C., Martins, M., Pascoal, C., Amaral, C., Serrano, I., Oliveira, M.J., Sackstein, R., et al. (2017). Inhibition of fucosylation in human invasive ductal carcinoma reduces E-selectin ligand expression, cell proliferation and ERk1/2 and P38MAPK activation. Mol. Oncol.12, 579-593. 
Carvalho, P.C., Silva, A.S., Todeschini, A.R., and Dias, W.B. (2018). Cellular glycosylation senses metabolic changes and modulates cell plasticity during epithelial to mesenchymal transition. Dev.

Din. 247, 481-491.

Cazet, A., Julien, S., Bobowski, M., Burchell, J., and Delannoy, P. (2010). Tumour-associated carbohydrate antigens in breast cancer. Breast Cancer Res. 12, 204.

Chikarmane, S.A., Tirumani, S.H., Howard, S.A., Jagannathan, J.P., and DiPiro, P.J. (2015). Metastatic patterns of breast cancer subtypes: what radiologists should know in the era of personalized cancer medicine. Clin. Radiol. 1, 1-10.

Choi, J., Kim, H., Jung, W., and Koo, J.S. (2013). Metabolic interaction between cancer cells and stromal cells according to breast cancer molecular subtype. Breast Cancer Res. 15, R78.

Curtis, C., Shah, S.P., Chin, S.F., Turashvili, G., Rueda, O.M., Dunning, M.J., Speed, D., Lynch, A.G., Samarajiwa, S., Yuan, Y., et al. (2012). The genomic and transcriptomic architecture of 2,000 breast tumours reveals novel subgroups. Nature 486, 346-352.

Duarte, H.O., Balmana, M., Mereiter, S., Osorio, H., Gomes, J., and Reis, C.A. (2017). Gastric cancer cell glycosylation as a modulator of the ErbB2 oncogenic receptor. Int. J. Mol. Sci. 18, 11.

Ferlay, J., Soerjomataram, I., Dikshit, R., Eser, S., Mathers, C., Rebelo, M., Parkin, D.M., Forman, D., and Bray, F. (2015). Cancer incidence and mortality worldwide: sources, methods and major patterns in GLOBOCAN 2012. Int. J. Cancer 5, E359-E386.

Foulkes, W.D., Smith, I.E., and Reis-Filho, J.S. (2010). Triple-negative breast cancer. N. Engl. J. Med. 363, 1938-1948.

Greville, G., McCann, A., Rudd, P., and Saldova, R. (2016). Epigenetic regulation of glycosylation and the impact on chemo-resistance in breast and ovarian cancer. Epigenetics 11, 845-857.

Han, D., Wu, G., Chang, C., Zhu, F., Xiao, Y., Li, Q., Zhang, T., and Zhang, L. (2015). Disulfiram inhibits TGF- $\beta$-induced epithelialmesenchymal transition and stem-like features in breast cancer via ERK/NFKB/Snail pathway. Oncotarget 6, 40907-40919.

Henry, N.L. and Hayes, D.F. (2012). Cancer biomarkers. Mol. Oncol. 6, 140-146.

Higai, K., Ichikawa, A., and Matsumoto, K. (2006). Binding of sialyl LewisX antigen to lectin-like receptors on NK cells induces cytotoxicity and tyrosine phosphorylation of a $17-\mathrm{kD}$ a protein. Biochim. Biophys. Acta 1760, 1355-1363.

Howlader, N., Altekruse, S.F., Li, C.I., Chen, V.W., Clarke, C.A., Ries, L.A., and Cronin, K.A. (2014). US incidence of breast cancer subtypes defined by Joint hormone receptor and HER2 status. J. Natl. Cancer Inst. 106, 055.

Jeon, M., Kim, H., Jung, H., and Koo, J.S. (2013). Expression of cell metabolism-related genes in different molecular subtypes of triple-negative breast cancer. Tumori. J. 99, 555-564.

Jones, R.B., Dorsett, K.A., Hjelmeland, A.B., and Bellis, S.L. (2018). The ST6Gal-I sialyltransferase protects tumor cells against hypoxia by enhancing HIF-1 $\alpha$ signaling. J. Biol. Chem. 11, 4663-4673.

Julien, S., Krzewinski-Recchi, M.A., Harduin-Lepers, A., Gouyer, V., Huet, G., Le Bourhis, X., and Delannoy, P. (2001). Expression of sialyl-Tn antigen in breast cancer cells transfected with the human CMP-Neu5Ac: GalNAc $\alpha 2,6$-sialyltransferase (ST6Gal-Nac I) cDNA. Glycoconj. J. 18, 883-893.

Julien, S., Ivetic, A., Grigoriadis, A., QiZe, D., Burford, B., Sproviero, D., Picco, G., Gillett, C., Papp, S.L., Schaffer, L., et al. (2011). Selectin ligand sialyl-Lewis $x$ antigen drives metastasis of hormonedependent breast cancers. Cancer Res. 24, 7683-7693. 
Julien, S., Videira, P.A., and Delannoy, P. (2012). Sialyl-tn in cancer: (how) did we miss the target? Biomolecules 4, 435-466.

Jung, Y., Fattet, L., and Yang, J. (2015a). Molecular pathways: linking tumor microenvironment to epithelial-mesenchymal transition in metastasis. Clin. Cancer Res. 21, 962-968.

Jung, S., Li, C., Duan, J., Lee, S., Kim, K., Park, Y., Yang, Y., Kim, K.I., Lim, J.S., Cheon, C.I., et al. (2015b). TRIP-Br1 oncoprotein inhibits autophagy, apoptosis, and necroptosis under nutrient/serumdeprived condition. Oncotarget 30, 29060-29075.

Khan, A., Fornes, O., Stigliani, A., Gheorghe, M., Castro-Mondragon, J.A., van der Lee, R., Bessy, A., Cheneby, J., Kulkarni, S.R., Tan, G., et al. (2018). JASPAR 2018: update of the open-access database of transcription factor binding profiles and its web framework. Nucleic Acids Res. 46, D26o-D 266.

Kim, S., Kim, H., Jung, H., and Koo, J.S. (2013). Metabolic phenotypes in triple-negative breast cancer. Tumour Biol. 34, 1699-1712.

Koike, T., Kimura, N., Miyazaki, K., Yabuta, T., Kumamoto, K., Takenoshita, S., Chen, J., Kobayashi, M., Hosokawa, M., Taniguchi, A., et al. (2004). Hypoxia induces adhesion molecules on cancer cells: a missing link between Warburg effect and induction of selectin-ligand carbohydrates. Proc. Natl. Acad. Sci. USA 21, 8132-8137.

Kondaveeti, Y., Guttilla Reed, I.K., and White, B.A. (2015). Epithelial-mesenchymal transition induces similar metabolic alterations in two independent breast cancer cell lines. Cancer Lett. 364, 44-58.

Kuo, C.Y., Cheng, C.T., Hou, P., Lin, Y.P., Ma, H., Chung, Y., Chi, K., Chen, Y., Li, W., Kung, H.J., et al. (2016). HIF-1- $\alpha$ links mitochondrial perturbation to the dynamic acquisition of breast cancer tumorigenicity. Oncotarget 7, 34052-34069.

Kyselova, Z., Mechref, Y., Kang, P., Goetz, J.A., Dobrolecki, L.E., Sledge, G.W., Schnaper, L., Hickey, R.J., Malkas, L.H., and Novotny, M.V. (2008). Breast cancer diagnosis and prognosis through quantitative measurements of serum glycan profiles. Clin. Chem. 7, 1166-1175.

Li, L. and Li, W. (2015). Epithelial mesenchymal transition in human cancer: comprehensive reprogramming of metabolism, epigenetics, and differentiation. Pharmacol. Ther. 150, 33-46.

Lucena, M.C., Carvalho, C.P., Donadio, J.L., Oliveira, I.A., de Queiroz, R.M., Marinho-Carvalho, M.M., Sola-Penna, M., de Paula, I.F., Gondim, K.C., McComb, M.E., et al. (2016). Epithelial mesenchymal transition induces aberrant glycosylation through hexosamine biosynthetic pathway activation. J. Biol. Chem. 291, 12917-12929.

Lundgren, K., Holm, C., and Landberg, G. (2007). Hypoxia and breast cancer: prognostic and therapeutic implications. Cell. Mol. Life Sci. 64, 3233-3247.

Mahmoodi, N., Motamed, N., Paylakhi, S.H., and O Mahmoodi, N. (2015). Comparing the effect of silybin and silybin Advanced ${ }^{\mathrm{TM}}$ on viability and HER2 expression on the human breast cancer $\mathrm{SKBR}_{3}$ cell line by no serum starvation. Iran J. Pharm. Res. 2, 521-530.

Marchiq, I. and Pouyssegur, J. (2016). Hypoxia, cancer metabolism and the therapeutic benefit of targeting lactate/H+ symporters. J. Mol. Med. 94, 155-171.

Mejias-Luque, R., Lopez-Ferrer, A., Garrido, M., Fabra, A., and de Bolos, C. (2007). Changes in the invasive and metastatic capacities of $\mathrm{HT}-29 / \mathrm{M} 3$ cells induced by the expression of fucosyltransferase 1. Cancer Sci. 7, 1000-1005. 
Milde-Langosch, K., Karn, T., Schmidt, M., zu Eulenburg, C., Oliveira-Ferrer, L., Wirtz, R.M., Schumacher, U., Witzel, I., Schutze, D., and Muller, V. (2014). Prognostic relevance of glycosylation associated genes in breast cancer. Breast Cancer Res. Treat. 145, 295-305.

Monzavi-Karbassi, B., Pashov, A., and Kieber-Emmons, T. (2013). Tumor-associated glycans and immune surveillance. Vaccines (Basel) 1, 174-203.

Natoni, A. and O'Dwyer, M.E. (2016). Targeting selectins and their ligands in cancer. Front Oncol. 18, 93.

Nutt, J.E. and Lunec, J. (1996). Induction of metalloproteinase (MMP1) expression by epidermal growth factor (EGF) receptor stimulation and serum deprivation in human breast tumour cells. Eur.

J. Cancer. 12, 2127-2135.

Peixoto, A., Fernandes, E., Gaiteiro, C., Lima, L., Azevedo, R., Soares, J., Cotton, S., Parreira, B., Neves, M., Amaro, T., et al. (2016). Hypoxia enhances the malignant nature of bladder cancer cells and concomitantly antagonizes protein $O$-glycosylation extension. Oncotarget 7, 63138-63157.

Perou, C.M., Sorlie, T., Eisen, M.B., van de Rijn, M., Jeffrey, S.S., Rees, C.A., Pollack, J.R., Ross, D.T., Johnsen, H., Akslen, L.A., et al. (2000). Molecular portraits of human breast tumours. Nature. 406, 747-752.

Pinho, S.S. and Reis, C.A. (2015). Glycosylation in cancer: mechanisms and clinical implications. Nat. Rev. Cancer 15, 540-555.

Potapenko, I.O., Luders, T., Russnes. H.G., Helland, A., Sorlie, T., Kristensen, V.N., Nord, S., Lingjarde, O.C., Borresen-Dale, A.L., and Haakensen, V.D. (2015). Glycan-related gene expression signatures in breast cancer subtypes; relation to survival. Mol. Oncol. 4, 861-876.

Reis, C.A., Osorio, H., Silva, L., Gomes, C., and David, L. (2010). Alterations in glycosylation as biomarkers for cancer detection. J. Clin. Pathol. 63, 322-329.

Reshkin, S.J., Bellizzi, A., Albarani, V., Guerra, L., Tommasino, M., Paradiso, A., and Casavola, V. (2000). Phosphoinositide 3-kinase is involved in the tumor-specific activation of human breast cancer cell $\mathrm{Na}+/ \mathrm{H}+$ exchange, motility, and invasion induced by serum deprivation. J. Biol. Chem. 8, 53615369 .

Rhodes, D.R., Yu, J., Shanker, K., Deshpande, N., Varambally, R., Ghosh, D., Barrette, T., Pandey, A., and Chinnaiyan, A.M. (2004). A cancer microarray database and integrated datamining platform. Neoplasia 6, 1-6.

Schultz, M.J., Swindall, A.F., and Bellis, S.L. (2012). Regulation of the metastatic cell phenotype by sialylated glycans. Cancer Metastasis Rev. 3-4, 501-518.

Semenza, G.L. (2012). Hypoxia-inducible factors in physiology and medicine. Cell 148, 399-408.

Sewell, R., Backstrom, M., Dalziel, M., Gschmeissner, S., Karlsson, H., Noll, T., Gatgens, J., Clausen, H., Hansson, G.C., Burchell, J., et al. (2006). The ST6GalNAc-I sialyltransferase localizes throughout the Golgi and is responsible for the synthesis of the tumor-associated sialyl-Tn O-glycan in human breast cancer. J. Biol. Chem. 281, 3586-3594.

Shirure, S., Liu, T., Delgadillo, F., Cuckler, C.M., Tees, D.F., Benencia, F., Goetz, D.J., and Burdick, M.M. (2015). CD44 variant isoforms expressed by breast cancer cells are functional $E$ - selectin ligands under flow conditions. Am. J. Physiol. Cell Physiol. 308, C68-C78.

Tan, Z., Wang, C., Li, X., and Guan, F. (2018). Bisecting N-acetylglucosamine structures inhibit hypoxia-induced epithelial-mesenchymal transition in breast cancer cells. Front. Physiol. 9, 210. 
Vaupel, P. and Hockel, M. (2000). Blood supply, oxygenation status and metabolic micromilieu of breast cancers: characterization and therapeutic relevance. Int. J. Oncol. 17, 869-879.

Wang, W., He, Y.F., Sun, Q.K., Wang, Y., Han, X.H., Peng, D.F., Yao, Y.W., Ji, C.S., and Hu, B. (2014a). Hypoxia-inducible factor $1 \alpha$ in breast cancer prognosis. Clin. Chim. Acta 428, 32-37.

Wang, F., Chang, M., Shi, Y., Jiang, L., Zhao, J., Hai, L., Sharen, G., and Du, H. (2014b). Downregulation of hypoxia-inducible factor-1 suppresses malignant biological behavior of triple-negative breast cancer cells. Int. J. Clin. Exp. Med. 11, 3933-3940.

Wu, C.Y., Guo, X.Z., and Li, H.Y. (2015). Hypoxia and serum deprivation protected MiaPaCa-2 cells from KAl1-induced proliferation inhibition through autophagy pathway activation in solid tumors. Clin. Transl. Oncol. 3, 201-208.

Yakisich, J.S., Venkatadri, R., Azad, N., and Yver, A.K.V. (2017). Chemoresistance of lung and breast cancer cells growing under prolonged periods of serum starvation. J. Cell Physiol. 8, 2033-2043.

Ye, Q., Kantonen, S., and Gomez-Cambronero, J. (2013). Serum deprivation confers the MDA-MB231 breast cancer line with an EGFR/JAK3/PLD2 system that maximizes cancer cell invasion. Mol. Biol. $4,755-766$.

Yevshin, I.S., Sharipov, R.N., Valeev, T.F., Kel, A., and Kolpkov, F. (2017). GTRD: a database of transcription factor binding sites identified by ChIP-seq experiments. Nucleic Acids Res. 45, D61-D67.

Zhuo, Y. and Bellis, S.L. (2011). Emerging role of $\alpha 2,6$-sialic acid as a negative regulator of galectin binding and function. J. Biol. Chem. 8, 5935-5941.

Zi, C., Wu, Z., Wang, J., Huo, Y., Zhu, G., Wu, S., and Bao, W. (2013). Transcriptional activity of the FUT1 gene promoter region in pigs. Int. J. Mol. Sci. 14, 24126-24134. 
Table 1: Antibodies and lectins used for Western blot (WB) and immunofluorescence (IF).

\begin{tabular}{|c|c|c|c|c|c|}
\hline \multirow{2}{*}{$\begin{array}{c}\text { Antibody Clone/ } \\
\text { Lectin }\end{array}$} & \multirow{2}{*}{ Antigen } & \multicolumn{2}{|c|}{ Working Dilution } & \multirow{2}{*}{$\begin{array}{c}\text { Blocking agent } \\
\text { WB }\end{array}$} & \multirow{2}{*}{ Supplier } \\
\hline & & IF & WB & & \\
\hline $\begin{array}{l}\text { E-Cadherin } \\
\left(24 \mathrm{E}_{10}\right)\end{array}$ & E-cadherin & $1: 100$ & - & - & $\begin{array}{l}\text { Cell Signaling } \\
\text { Technology }\end{array}$ \\
\hline $\begin{array}{c}\mathrm{HIF}_{1} \alpha\left(\mathrm{H}_{1} \text { alpha }\right. \\
67-\mathrm{NB})\end{array}$ & $\mathrm{HIF}_{1} \alpha$ & $1: 50$ & $1: 500$ & $\begin{array}{c}5 \% \text { non-fat milk } \\
\text { in TBST }\end{array}$ & $\begin{array}{c}\text { Novus } \\
\text { Biologicals }\end{array}$ \\
\hline $\begin{array}{l}\alpha-\text { Tubulin } \\
\left(\mathrm{DM}_{1} \mathrm{~A}\right)\end{array}$ & $\alpha$-Tubulin & $1: 750$ & - & - & Sigma-Aldrich \\
\hline$\beta$-actin (I-19) & $\beta$-actin & - & $1: 2000$ & $\begin{array}{c}5 \% \text { non-fat milk } \\
\text { in TBST }\end{array}$ & $\begin{array}{c}\text { Santa Cruz } \\
\text { Biotechnology }\end{array}$ \\
\hline Vimentin (Vg) & Vimentin & $1: 500$ & - & - & Dako \\
\hline $\begin{array}{c}\text { Aleuria aurantia } \\
\text { lectin (AAL) }\end{array}$ & $\begin{array}{l}\text { Fuc } \alpha_{6 G} \text { lcNAc } \\
\text { Fuc } \alpha_{3} \text { GlcNAc } \\
\text { Fuc } \alpha_{4} \text { GlcNAc }\end{array}$ & - & $1: 3000$ & $2 \%$ PVP in TBS & Vector Labs \\
\hline $\begin{array}{l}\text { Sambrucus } \\
\text { Nigra lectin } \\
\text { (SNA) }\end{array}$ & $\begin{array}{c}\text { Neu5Aco6Gal/ } \\
\text { GalNAc }\end{array}$ & - & 1:3000 & $2 \%$ PVP in TBS & Vector Labs \\
\hline
\end{tabular}




\section{Figure 1}

A

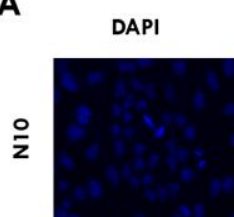

$\alpha-$ Tubulin
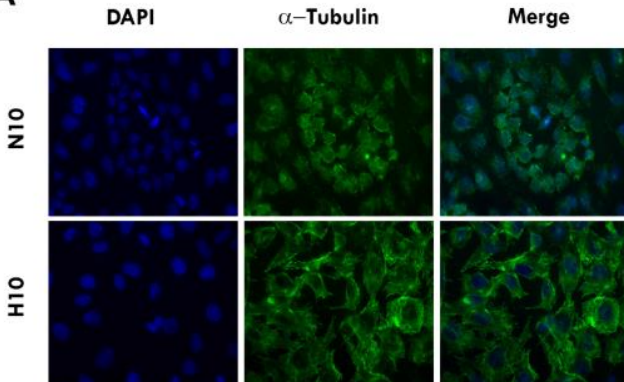

C
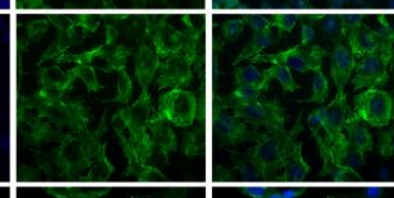

₹
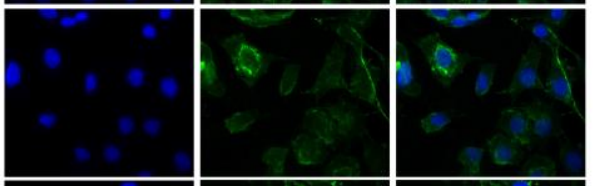

오
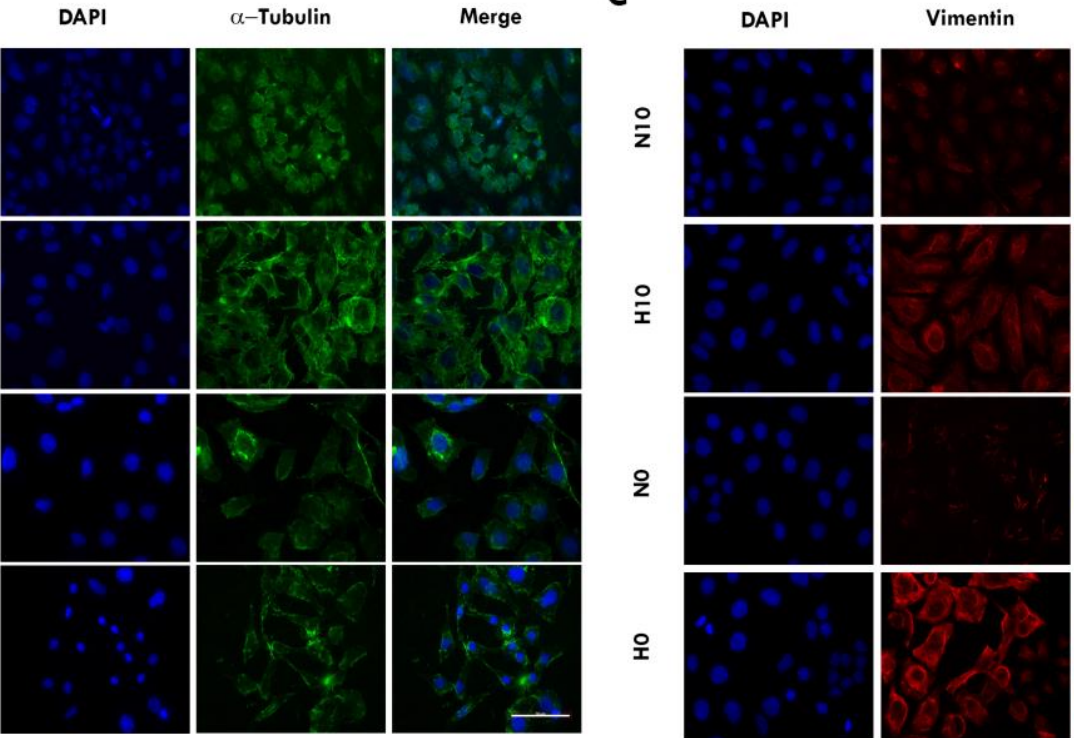

Merge

옾
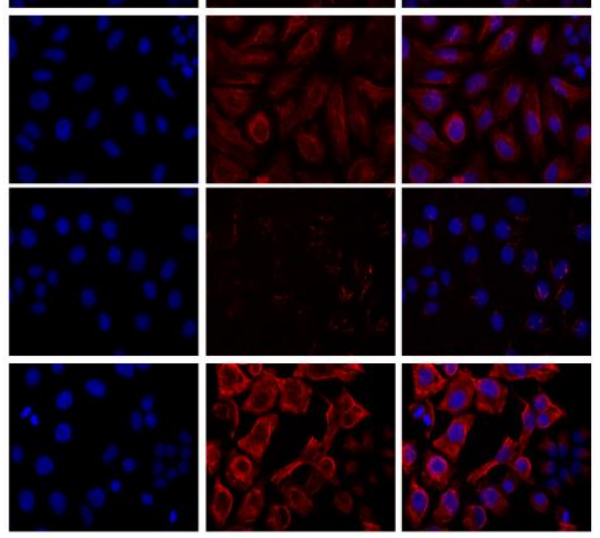

B

DAPI

E-cadherin

Merge
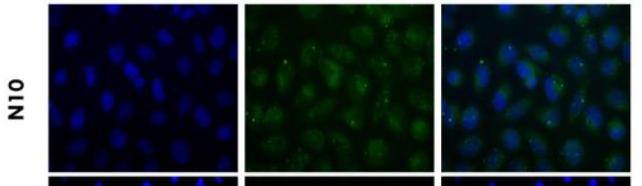

옾
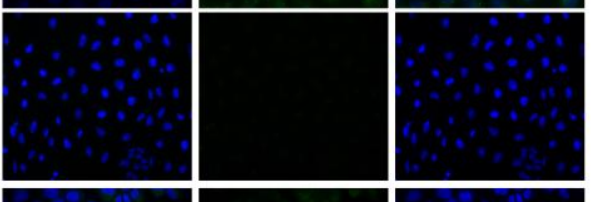

D
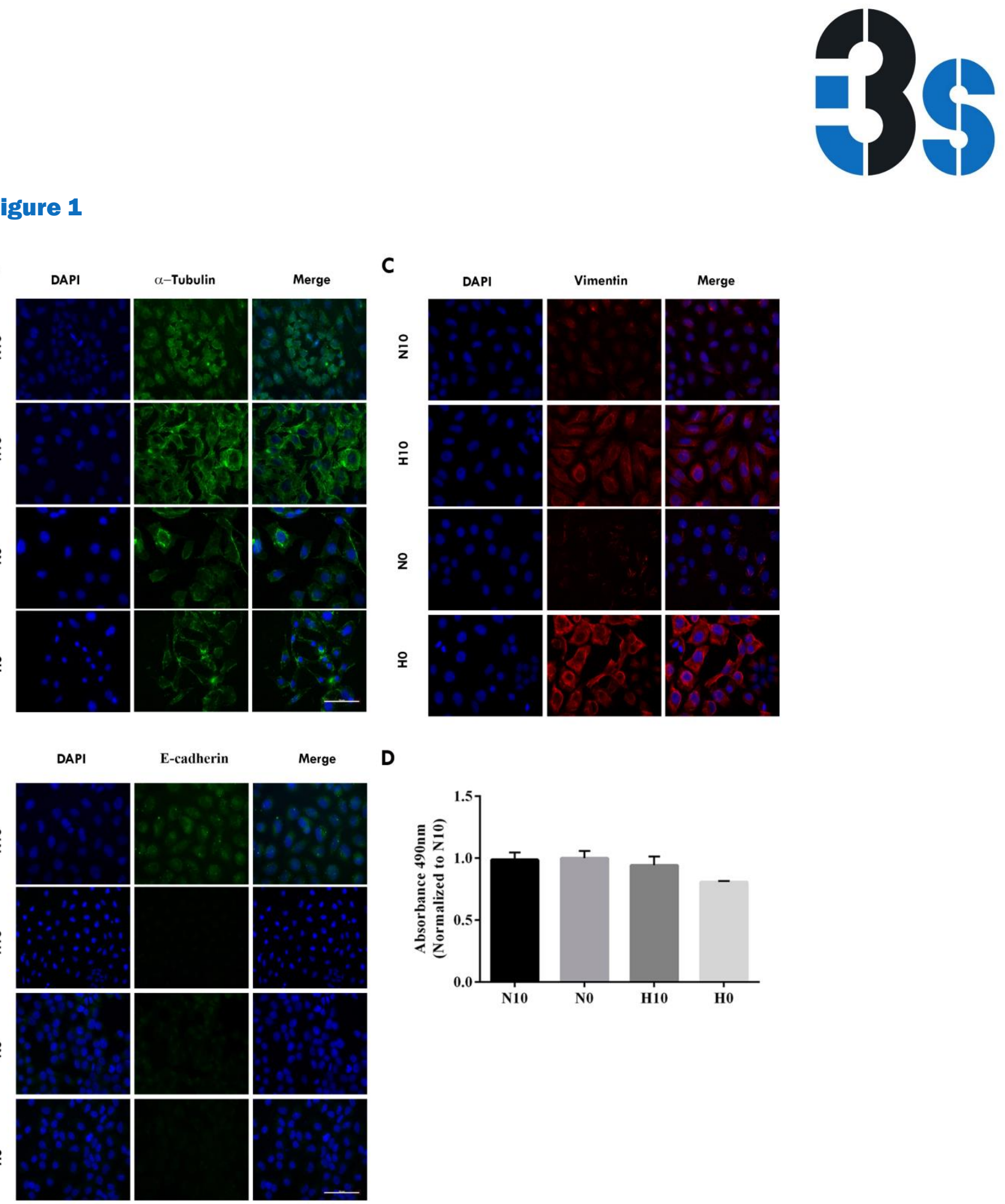

Fig. 1. Morphological changes and EMT activation of MDA-MB-231 induced by hypoxia and serum deprivation. (A) Effect of hypoxia and serum deprivation on MDA-MB-231 cells' morphology and cytoskeleton organization ( $\alpha$ tubulin staining) after $48 \mathrm{~h}$ of exposure to normoxia with serum supplementation ( $\left.21 \% \mathrm{O}_{2}, 10 \% \mathrm{FBS}-\mathrm{N}_{10}\right)$, hypoxia with serum supplementation $\left(1 \% \mathrm{O}_{2}, 10 \% \mathrm{FBS}-\mathrm{H}_{1} 0\right)$ and normoxia and hypoxia without FBS supplementation, No and $\mathrm{Ho}$, respectively. Effect of hypoxia and serum deprivation on $\mathrm{E}$-cadherin $(\mathrm{B})$ and vimentin (C) expression after $48 \mathrm{~h}$ of exposure to $\mathrm{N} 10, \mathrm{No}, \mathrm{H} 10$ and Ho conditions. Scale bar represents $50 \mu \mathrm{m}$. (D) Cell viability of MDA-MB-231 breast cancer lines determined by MTS assay after $48 \mathrm{~h}$ of exposure to $\mathrm{N}_{10}, \mathrm{H}_{10}$, No and Ho. 


\section{Figure 2}
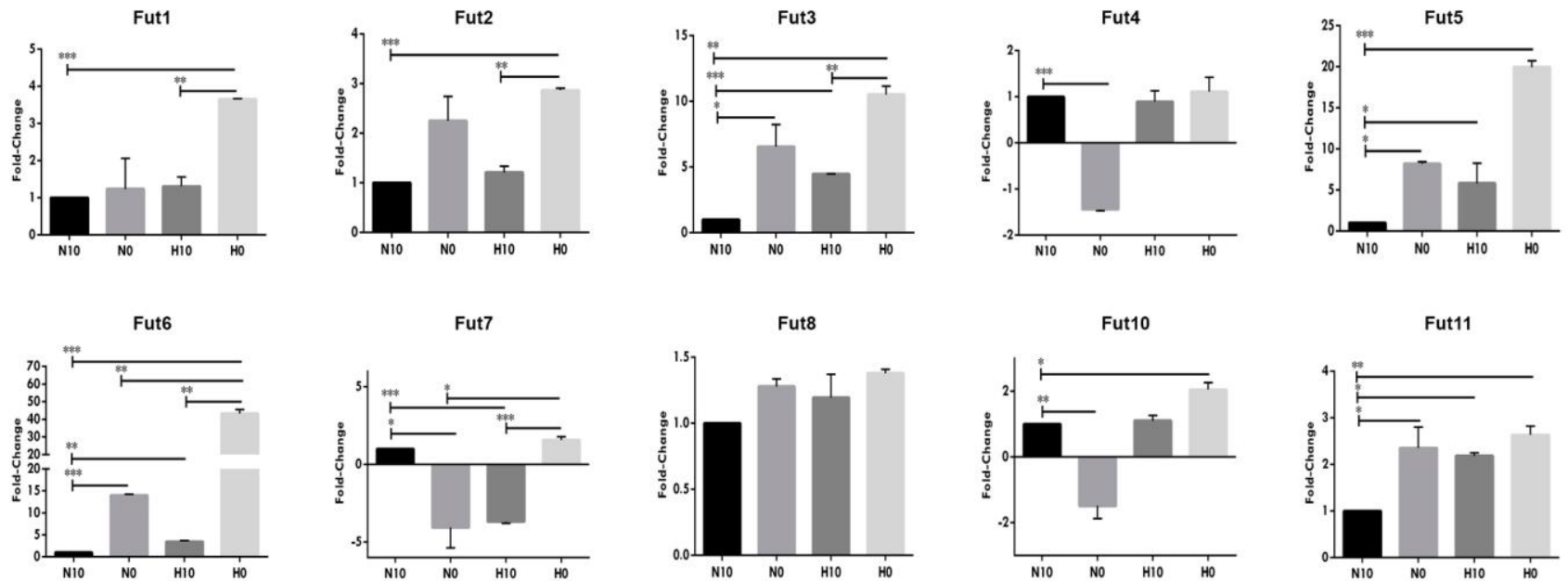

Fig. 2 Fucosyltransferase transcription analysis in MDA-MB-231 under hypoxia and serum deprivation.

Quantitative real-time polymerase (qRT-PCR) showing levels of expression of FUT genes in MDA-MB-231 cells relative to the N10 condition and normalized to the expression of ACTB/PPIA housekeeping genes. RNA was collected after $48 \mathrm{~h}$ of exposure to normoxia with serum supplementation $\left(21 \% \mathrm{O}_{2}, 10 \% \mathrm{FBS}-\mathrm{N}_{1} 0\right)$, hypoxia with serum supplementation $\left(1 \% \mathrm{O}_{2}, 10 \% \mathrm{FBS}-\mathrm{H}_{1} \mathrm{O}\right)$ and normoxia and hypoxia without FBS supplementation, No and Ho, respectively. Graphs represent the average value of two independent experiments with three technical replicates. Significant values are as follows: $* p<0.05, * * p<0.01, * * * p<0.001$ (Student's $t$-test).

\section{Figure 3}

ST3Gal3

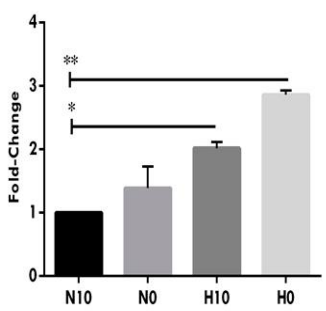

ST6GaINAC1

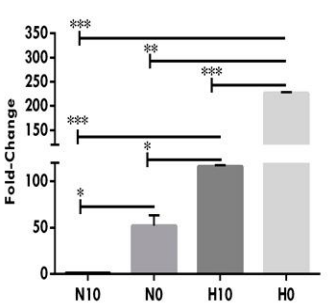

ST3Gal4

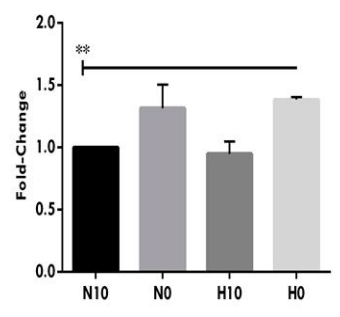

ST6GaINAc2

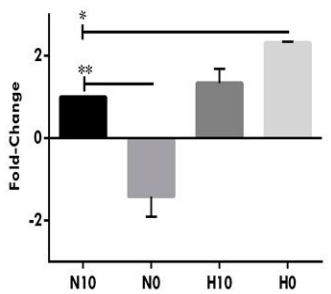

ST3Gal6

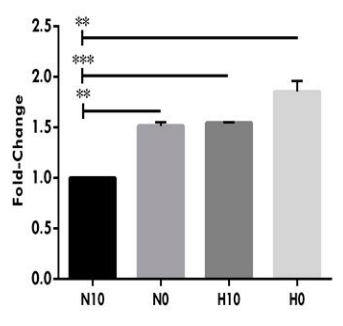

ST6GaINAC5

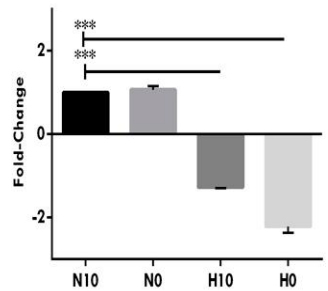

Fig. 3 Sialyltransferase transcription analysis in MDA-MB-231 under hypoxia and serum deprivation. qRT- PCR showing levels of expression of ST genes in MDA-MB-231 cells relative to the N10 condition and normalized to the expression of ACTB/PPIA housekeeping genes. RNA was collected after $48 \mathrm{~h}$ of exposure to normoxia with serum supplementation $\left(21 \% \mathrm{O}_{2}, 10 \% \mathrm{FBS}-\mathrm{N}_{1}\right.$ ) , hypoxia with serum supplementation $\left(1 \% \mathrm{O}_{2}, 10 \% \mathrm{FBS}-\mathrm{H}_{10}\right)$ and normoxia and hypoxia without FBS supplementation, No and Ho, respectively. Graphs represent the average value of two independent experiments with three technical replicates. Significant values are as follows: ${ }^{*} p<0.05, * * p<0.01, * * * p<0.001$ (Student's $t$ test). 


\section{Figure 4}

$\mathbf{A}$

\begin{tabular}{|c|c|c|c|c|c|}
\hline Gene & Range (All breast & & Range (Ba & & \\
\hline Gene Name & From & From & To & & \\
\hline FUT1 & 20,91 & 40,91 & 18,14 & 38,14 & 16,12 \\
\hline FUT2 & 4,58 & 24,58 & 7,39 & 27,39 & 17,37 \\
\hline FUT3 & 3,30 & 23,30 & 5,09 & 25,09 & 12,77 \\
\hline FUT4 & 17,75 & 37,75 & 15,35 & 35,35 & 35,82 \\
\hline FUT5 & 26,40 & 46,40 & 24,83 & 44,83 & 51,00 \\
\hline FUT6 & 26,84 & 46,84 & 22,68 & 42,68 & 25,54 \\
\hline FUT7 & 1,46 & 21,46 & 1,63 & 21,63 & 16,15 \\
\hline FUT8 & 31,98 & 51,98 & 25,74 & 45,74 & 58,30 \\
\hline FUT10 & 19,18 & 39,18 & 18,85 & 38,85 & 31,80 \\
\hline ST3GAL3 & 14,94 & 34,94 & 14,48 & 34,48 & 29,11 \\
\hline ST3GAL4 & 25,51 & 45,51 & 25,15 & 45,15 & 44,45 \\
\hline ST3GAL6 & $-2,49$ & 17,51 & 1,12 & 21,12 & 39,50 \\
\hline ST6GALNAC1 & $-2,82$ & 17,18 & $-2,50$ & 17,50 & 14,11 \\
\hline
\end{tabular}

B

FUT5 expression

ST3Gal6 expression
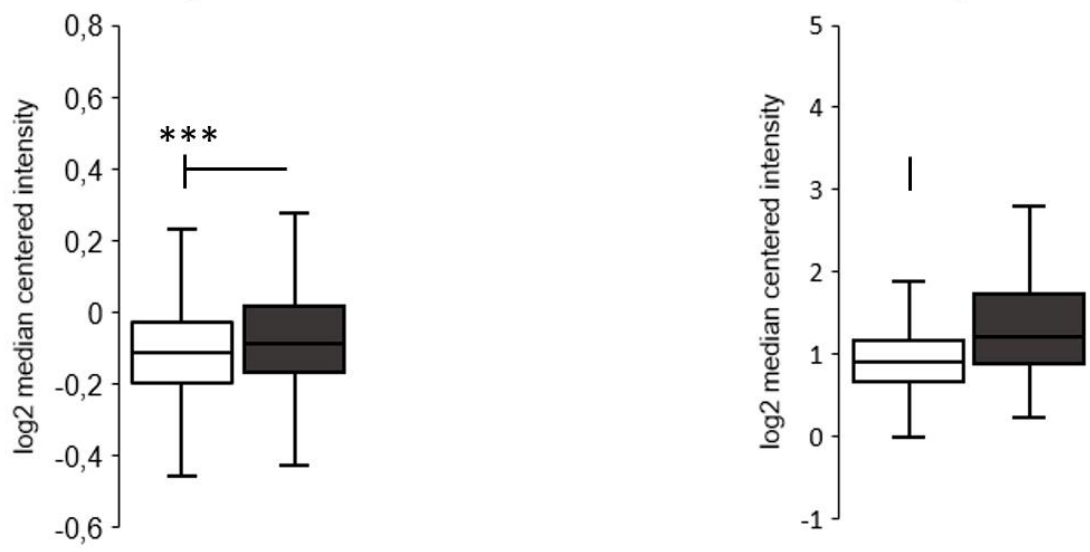

$\square$ All breast carcinomas

$\square$ All breast carcinomas

- Basal-like

Fig. 4 In silico analysis of fucosyltransferase and sialyltransferase expression in MDA-MB-231 cell line and human breast carcinomas.

(A) Intrinsic fucosyltransferase and sialyltransferase gene expression of MDA-MB-231 compared to 54 other breast cancer cell lines. The raw data on transcription levels were extracted from the Barretina CellLine data deposited in the OncomineTM database. Based on normalized transcription values of all 56 breast cancer cell lines that were included in the dataset, a range of average expression values (median \pm 10 ) for breast cancer cell lines was defined for each gene. (B) Gene expression analysis of FUT5 and ST3GAL6 in overall human breast carcinomas and TNBC subtypes. The raw data is derived from Curtis Breast data deposited in the OncomineTM database. All breast carcinomas, $\mathrm{n}=1989 ;$ TNBC, $\mathrm{n}=331 . * * * p<0.0001$ (Student's $t$-test). 


\section{Figure 5}

A

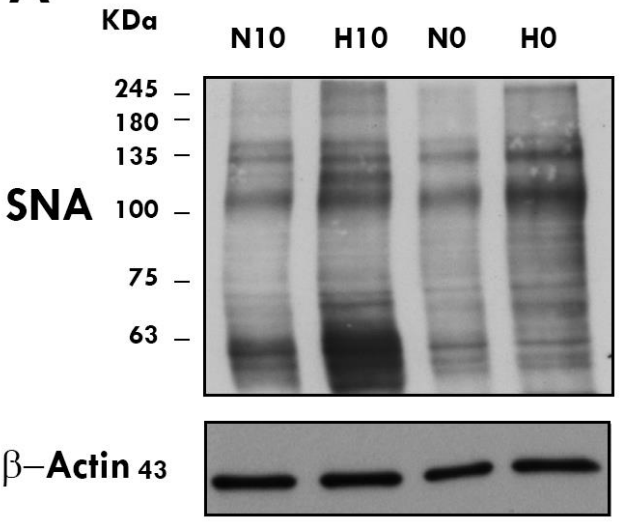

B

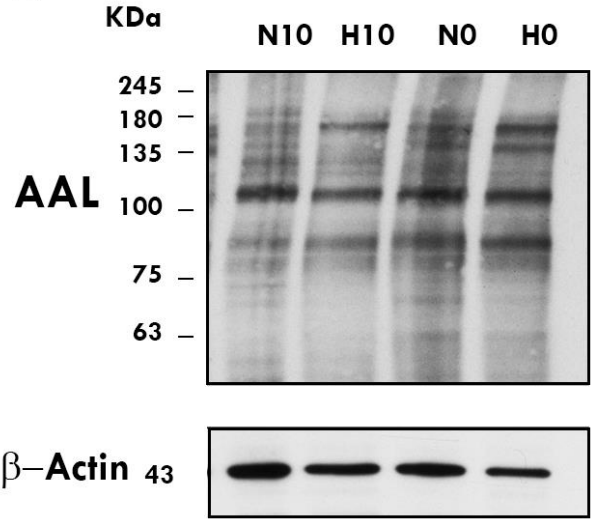

Fig. 5 Hypoxia and serum deprivation induces aberrant glycosylation of MDA-MB-231.

Sialylation and fucosylation profile MDA-MB-231 breast cancer cell line determined by SNA (A) and AAL (B) lectin blots of the cells subjected to different cell culture conditions: normoxia with serum supplementation $\left(21 \% \mathrm{O}_{2}, 10 \%\right.$ FBS - $\mathrm{N}_{10}$ ), hypoxia with serum supplementation $\left(1 \% \mathrm{O}_{2}, 10 \% \mathrm{FBS}-\mathrm{H}_{10}\right)$ and normoxia and hypoxia without FBS supplementation, No and $\mathrm{Ho}$, respectively. The corresponding $\beta$-actin immunoblots are shown below.

\section{Figure 6}

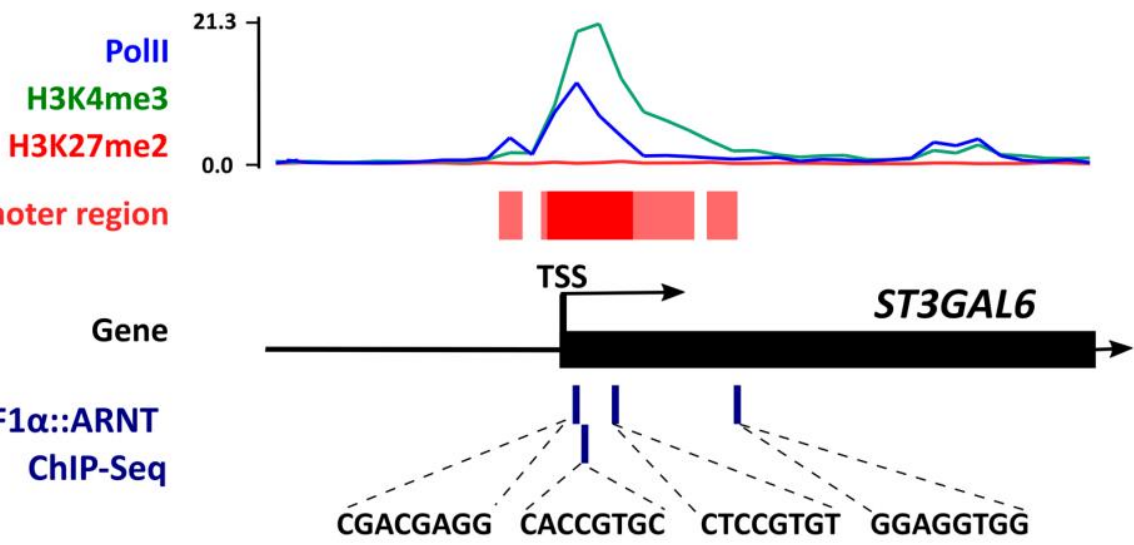

Fig. 6 Hif-1 $\alpha$ transcription factor interacts with glycosylatransferase promoters.

Transcription factor binding sites in promoters of the differentially expressed $S T_{3} G A L 6$ gene were analyzed using known DNA-binding motifs described in the JASPAR database (Khan et al., 2018). ChIPseq experiment information for HIF-1 $\alpha$ was collected and analysed from GTRD database (v18.01) (Yevshin et al., 2017). ChIP-seq binding signal (blue bars) for HIF-1 $\alpha$ ::ARNT was detected in the promoter region of the ST3GAL6 gene. Presence of the transcription factor $\mathrm{HIF}-1 \alpha$ is correlated with opening of chromatin $\left(\mathrm{H}_{3} \mathrm{~K}_{4} \mathrm{me}_{3}\right)$ and activation of gene transcription (Pol II), indicating a possible regulatory mechanism for those genes under hypoxic conditions. Information for $\mathrm{H}_{3} \mathrm{~K}_{4} \mathrm{me}_{2}, \mathrm{H}_{3} \mathrm{~K}_{2} \mathrm{mme}_{3}$, Pol II and the higher content of GCs in the promoter region (dark red) were extracted from Emsembl 92 release 2018 (www.ensembl.org). TSS, Transcription start site. 
Supplementary Table. Primer sequences for gene expression analysis in MDA-MB-231 cells under normoxic, hypoxic and/or serum deprivation conditions..

\begin{tabular}{|c|c|c|}
\hline Gene & Primer sequences & Product size/bp \\
\hline $\begin{array}{c}\alpha 1,2 \text {-fucosyltransferses } \\
\text { FUT1 }_{1}\end{array}$ & $\begin{array}{l}\text { F:aaagactgaaggagcatatgattgc } \\
\text { R: tcaaacctggtcctctctagaacaa }\end{array}$ & 110 \\
\hline FUT2 & $\begin{array}{l}\text { F:gcggctagcgaagattcaag } \\
\text { R: tgatgttgaggctagcactggta }\end{array}$ & 67 \\
\hline $\begin{array}{c}\alpha 1,3 / 4 \text {-fucosyltransferses } \\
\mathrm{FUT}_{3}\end{array}$ & $\begin{array}{l}\text { F:caaaatgccaagggtggaca } \\
\text { R:ttggcctcaatcaatcctcct }\end{array}$ & 89 \\
\hline FUT4 & $\begin{array}{c}\text { F:aagccgttgaggcggttt } \\
\text { R:acagttgtgtatgagatttggaagct }\end{array}$ & 88 \\
\hline FUT5 & $\begin{array}{c}\text { F:aagccgttgaggcggttt } \\
\text { R:acagttgtgtatgagatttggaagct }\end{array}$ & 70 \\
\hline FUT6 & $\begin{array}{l}\text { F:caaagccacatcgcattgaa } \\
\text { R:atccccgttgcagaacca }\end{array}$ & 95 \\
\hline FUT7 & $\begin{array}{l}\text { F:ccgcttctacctgtcctttga } \\
\text { R:gcgttgcgccagaatttct }\end{array}$ & 250 \\
\hline FUT8 & $\begin{array}{l}\text { F: ccatttcaggtttgtttggtag } \\
\text { R: attggtcccgcttctcactt }\end{array}$ & 200 \\
\hline FUT10 & $\begin{array}{l}\text { F:caccgtctttctgcttgtca } \\
\text { R:ccttcctttcaaacttcccc }\end{array}$ & 62 \\
\hline FUT11 & $\begin{array}{l}\text { F:gctttggcaatgtggaagaga } \\
\text { R:gccaataatcttgcagccac }\end{array}$ & 69 \\
\hline $\begin{array}{c}\alpha 2,3 \text {-sialyltransferses } \\
\mathrm{ST}_{3} \mathrm{Gal}_{3}\end{array}$ & $\begin{array}{c}\text { F:ggtggcagtcgcaggattt } \\
\text { R:catgcgaacggtctcatagtagtg }\end{array}$ & 76 \\
\hline $\mathrm{ST}_{3} \mathrm{Gal}_{4}$ & $\begin{array}{l}\text { F:cctggtagctttcaaggcaatg } \\
\text { R:cctttcgcacccgcttct }\end{array}$ & 74 \\
\hline $\mathrm{ST}_{3} \mathrm{Gal} 6$ & $\begin{array}{l}\text { F:cggctgattttagaaagattgctt } \\
\text { R:cggctgattttagaaagattgctt }\end{array}$ & 90 \\
\hline $\begin{array}{l}\alpha 2,6 \text {-sialyltransferses } \\
\text { ST6GaINAc1 }\end{array}$ & $\begin{array}{l}\text { F: tccaagggaacacttgaacca } \\
\text { R: gcctcaggacctacagcaat }\end{array}$ & 100 \\
\hline ST6GaINAc2 & $\begin{array}{c}\text { F: ctttgccctgtacttctcg } \\
\text { R: cagcactggaatggagaga }\end{array}$ & 200 \\
\hline ST6GalNAc5 & $\begin{array}{l}\text { F: ggatcccaatcacccttcag } \\
\text { R: tagcaagtgattctggtttcca }\end{array}$ & 200 \\
\hline $\begin{array}{l}\text { Housekeeping genes } \\
\text { ACTB }\end{array}$ & $\begin{array}{l}\text { F: agaaaatctggcaccacacc } \\
\text { R: tagcacagcctggatagcaa }\end{array}$ & 173 \\
\hline PPIA & $\begin{array}{l}\text { F: agacaaggtcccaaagac } \\
\text { R: accaccctgacacataaa }\end{array}$ & 118 \\
\hline
\end{tabular}


Supplementary Figure 1.

A
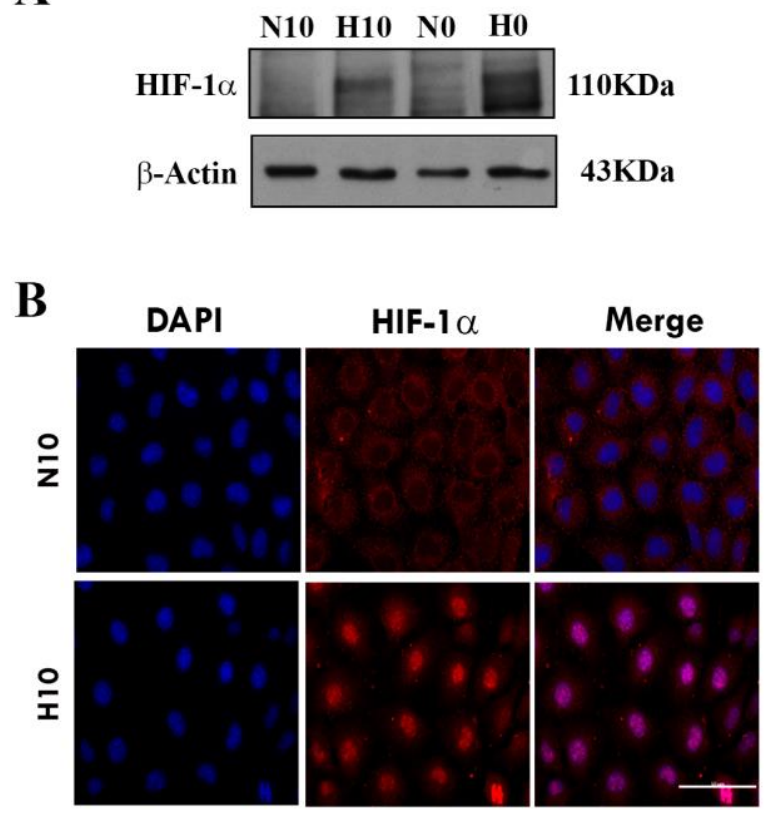

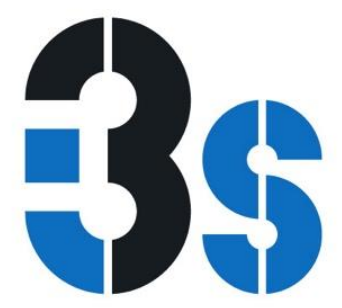

(A) Western blot analysis of HIF-1 $\alpha$ in MDAMB-231 breast cancer cell line after $48 \mathrm{~h}$ of exposure to different cell culture conditions. Normoxia with serum supplementation ( $21 \%$ $\left.\mathrm{O}_{2}, 10 \% \mathrm{FBS}-\mathrm{N} 10\right)$, hypoxia with serum supplementation $\left(1 \% \mathrm{O}_{2}, 10 \% \mathrm{FBS}-\mathrm{H}_{1} \mathrm{O}\right)$ and normoxia and hypoxia without FBS supplementation, No and $\mathrm{Ho}$, respectively. The corresponding $\beta$-actin immunoblots are also shown. (B) HIF-1 $\alpha$ immunofluorescence in MDA-MB-231 cells exposed to $\mathrm{N}_{10}$ and $\mathrm{H}_{10}$. Scale bar represents $50 \mu \mathrm{m}$.

Supplementary Figure 2.

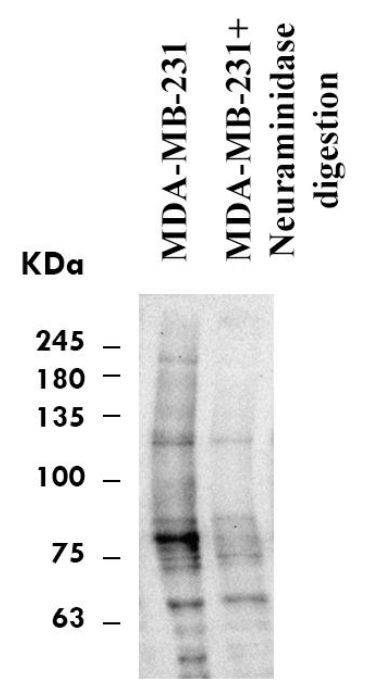

SNA lectin specificity in MDA-MB-231 cells. The $\mathrm{N}_{10}\left(21 \% \mathrm{O}_{2}, 10 \% \mathrm{FBS}\right)$ condition lysate was subjected to neuraminidase digestion and run in parallel to equal amounts of control $\mathrm{N}_{10}$ sample and subjected to SNA detection. 